\title{
Analysis of electric consumption: a study in the excavation area of the modern coal mine
}

\author{
Vyacheslav Voronin*, Fedor Nepsha, and Aleksandr Ermakov \\ T.F. Gorbachev Kuzbass State Technical University, 28, Vesennyaya st., Kemerovo, 650000, Russia
}

\begin{abstract}
The growth in the power supply of coal mines over the past decades has had a significant impact on their power consumption. The use of outdated materials for assessing the coal mine energy characteristics may lead to large calculation errors. At the same time, the problem of reducing the energy intensity of coal mining does not lose its relevance. However, in order to achieve it, it is necessary to take into account the current level of development of the mechanized complex of excavation areas. The widespread introduction of SCADA systems and the development of methods for big data processing makes it possible to collect large arrays of measurements and study the power consumption of mining equipment. In this paper, on the basis of extensive arrays of electrical load measurements and technological parameters, a statistical analysis of the load of a modern Eickhoff SL 900 longwall shearer of the Kuzbass coal mine is carried out.
\end{abstract}

\section{Introduction}

In recent years, there have been significant fluctuations in coal prices. Steam coal prices were at a low level throughout 2020, driven by a slump in industrial production and lower electricity demand triggered by the Covid-19 pandemic. In the second quarter of 2020, prices reached their lowest in the last 16 years, however, by the fall, European prices climbed to an annual high. In Russia, coal production in 2020 amounted to 402.1 million tons, which is $8.9 \%$ less than in 2019 .

Cold winter of 2020-2021 in Western Europe and the USA showed that energy systems based on renewable energy sources still lack sufficient reliability in volatile climatic conditions. In this regard, a complete transition to "green" energy is not yet possible and coal-fired generation will play an important role in the overall energy balance for a long time.

According to the forecast of coal demand [1], under a favorable scenario, by 2040, the coal demand has to increase by $17 \%$ (compared to the level of 2018). The program for the development of the coal industry in Russia for the period up to 2035 [2] predicts a change in coal demand by 2035 in the range from -1.16 to $+13.95 \%$.

Despite the decline in coal prices, investments in the Russian coal industry continue to grow. According to [3], in 2019 the investment growth rate was $+16.9 \%$, and one of the main areas of investment is the development of production facilities. In addition, the program [2] includes technical re-equipment and intensification of coal production until 2025.

To achieve the planned indicators in the coming decades, there will be an increase in the power supply capacity of mechanized complexes of mining areas and, accordingly, an increase in the power consumption of coal mines. In the context of sharp fluctuations in prices for steam coal, in order to reduce the cost of coal production and ensure the competitiveness of products, coal enterprises are looking for modern technologies to improve their energy efficiency.

\section{The Problem Statement}

During the 1990s the specific power consumption of the coal mines of Kuzbass increased by an average of 1.52.3 times and had a tendency to further increase by 4.4$9.1 \%$ per year [6]. Over the past years, foreign energyintensive equipment has been actively introduced into coal mines, however, due to insufficient research, the potential for reducing specific power consumption remains unrealized. Reducing the energy intensity of coal mining can be achieved by modernizing mining equipment, improving coal mining technologies, reducing energy losses, introducing energy metering systems, and setting the rate of energy consumption. As noted in [4], in the energy balance of a coal mine, up to $70-80 \%$ falls to electrical energy. Accordingly, the potential for energy saving is also great due to a reduction in the power consumption of a coal mine (16$18 \%$ according to [5]). However, the development and implementation of energy saving measures should be preceded by an analysis of the use of energy resources.

With the introduction of Internet of Things (IoT) technology in coal mines, it becomes possible to collect and record a large amount of measurement information (Big Data). Currently, Big Data is one of the most frequently mentioned terms within the framework of the "Digital Mine" concept, behind the term "Automation"

\footnotetext{
Corresponding author: voroninva@kuzstu.ru
} 
(IoT is in third place) [7]. Big Data in coal mines can be used to improve the safety of mining operations, predict equipment failures, control and maintain mining machines, create digital twins, and others [8]. In addition, when introducing technologies for intelligent control of power flows into the power supply systems of coal mines (based on second generation FACTS devices), Big Data can be used to control the operating modes of the coal mine power supply.

The relative simplicity of collecting large amount of measurements using the SCADA system allows largescale studies of the power consumption of a coal mine. Simultaneous analysis of both electrical and technological indicators makes it possible to reveal their mutual influence. The results of these studies can be used to update the indicators of electricity consumption of coal mines, given in the students and reference books, to analyze the operating modes of mining equipment, as well as to identify ways to increase the energy efficiency of coal mining.

\section{Materials and Methods}

The object of research is the excavation area of the coal mine located in the Kemerovo region.

According to various data, technological operations for coal mining consume from 5.5 to $18.7 \%$ of the total electricity consumption of a coal mine [6,9]. The main share in the structure of electricity consumption of coal mines falls to ventilation and drainage. However, with an increase in the load on the excavation area, even a slight reduction in specific power consumption can have a positive effect on the cost of coal production. Also of particular interest are the operating modes of mining machines of the excavation area. The nature of the power consumption of the excavation area is influenced by many technological and mining and geological parameters, and the nature of the electrical load is sharply variable, which makes it difficult to simulate the operating modes of the mechanized complex of the excavation area.

The excavaton area load is up to 20,000 tons / day, the operating mode is three-shift. The equipment of the excavation area includes: Eickhoff SL 900 longwall shearer; armored face conveyor SH PF 6/1142; reloader ST PF 6/1342; crusher SK 1114; mechanized support sections. The parameters of the electric equipment of the excavation area are presented in table 1.

With the help of the SCADA system, arrays of measurements were obtained: electric current load and active power of the shearer; shearer haulage speed; belt conveyor traffic flow. The measurement arrays were formed in the asynchronous polling mode with data recording only when they were changed by a value greater than that of the specified aperture. The server data update rate is 5 seconds. The measurement period covers the time interval from $09 / 11 / 2020$ to $11 / 22 / 2020$.

For data processing, the python programming language was used with pandas software libraries for data processing and analysis, sklearn libraries for cluster analysis and matplotlib and seaborn libraries for plotting graphs. In the course of the primary data processing, resampled was performed to obtain the same time stamps for all time series, non-working shifts were excluded, and the time shift of the array of traffic flow measurements was performed to take into account the time delay for coal transportation from the excavation area to the mine scales.

Table 1. Characteristics of excavation area equipment.

\begin{tabular}{|c|c|c|c|c|}
\hline No. & Equipment & $\begin{array}{c}\text { Rated } \\
\text { voltage, } \\
\mathrm{V}\end{array}$ & $\begin{array}{c}\text { Rated } \\
\text { power, } \\
\mathrm{kW}\end{array}$ & $\begin{array}{c}\text { Rated } \\
\text { production, } \\
\mathrm{t} / \mathrm{h}\end{array}$ \\
\hline 1 & $\begin{array}{c}\text { Longwall } \\
\text { shearer } \\
\text { Eickhoff SL } \\
900\end{array}$ & 3300 & 2104 & $3000-5000$ \\
\hline 2 & $\begin{array}{c}\text { Armored face } \\
\text { conveyor } \\
\text { SH PF 6/1142 }\end{array}$ & 3300 & $3 \times 1000$ & 3000 \\
\hline 3 & $\begin{array}{c}\text { Reloader ST } \\
\text { PF 6/1342 }\end{array}$ & 3300 & $200 /$ & 3600 \\
\hline 4 & $\begin{array}{c}\text { Crusher SK } \\
1114\end{array}$ & 3300 & 400 & 4000 \\
\hline
\end{tabular}

\section{Use Case}

After analyzing 181 working shifts of the excavation area, diagrams of the correlation between the shearer electricity consumption and the volume of coal mined by shifts and by days were built (Fig. 1).

There is a high degree of correlation between electricity consumption and coal production (correlation coefficient $\mathrm{R}=0.93$ ). The average daily coal production for the period under consideration was 20.2 thousand tons, which corresponds to the technical and economic indicators of the longwall excavation (20 000 tons). Average shift production is respectively 5427, 7809 and 7707 tons of coal for the first, second and third shifts. The difference in productivity is due to the presence of a maintenance shift.

The result of the data processing of the belt conveyor traffic flow (Fig. 2) showed that the productivity of the excavation area does not exceed $2692 \mathrm{t} / \mathrm{h}$ (with a confidence level of 0.99 ), which corresponds to the productivity of mining equipment (Table 1). The median value of the traffic flow is $874 \mathrm{t} / \mathrm{h}$, which indicates a possible increase in the productivity of the excavation area. 

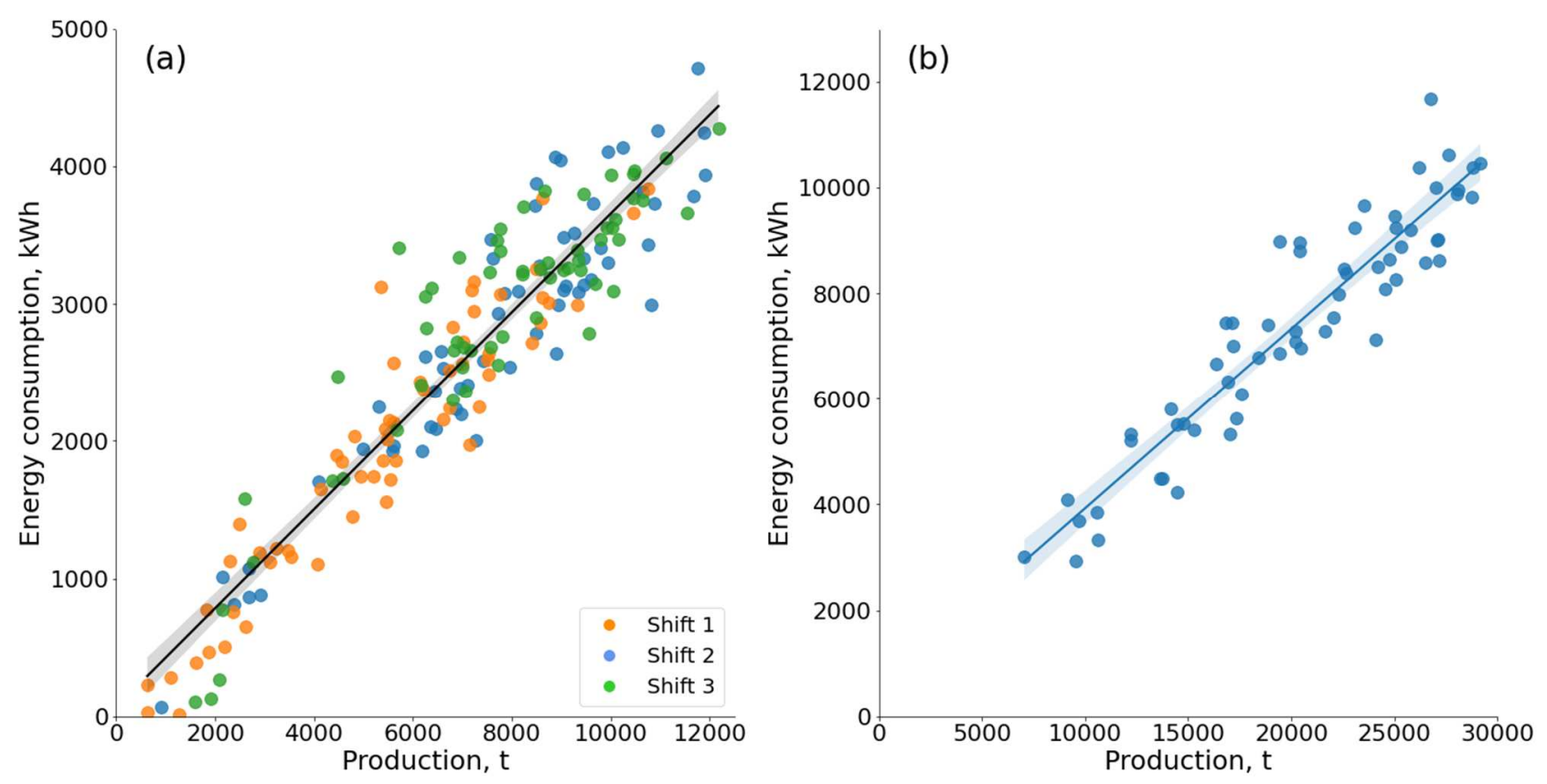

Fig. 1. Scatter plot of energy consumption and production of the excavation area by shifts (a) and days (b).

The shearer is the main technological machine that sets the load for all technological links of the excavation area and the mine as a whole. Its mode of operation directly affects the energy characteristics of a coal mine. One of the main technological indicators of the shearer operation is the haulage speed.

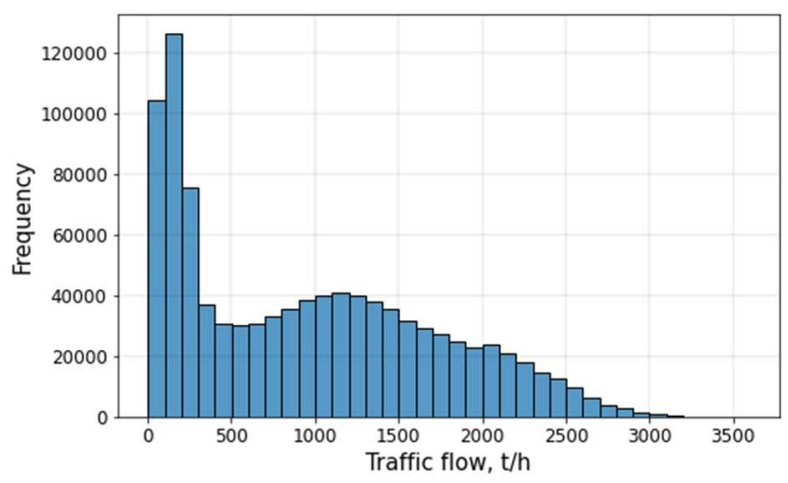

Fig. 2. Frequency histogram of the conveyor traffic flow.

To assess the influence of the haulage speed on the power consumption of the shearer, the array of measurements was processed, during which the original array was divided into separate time intervals, according to the criterion of changing the direction of movement of the shearer. To exclude end operations from consideration, as well as deviations from the normal operating mode, intervals with the time of movement of the shearer in one direction less than 10 minutes were removed from the resulting array. For each time interval, averaged indicators of haulage speed, traffic flow and electrical load were determined.

The diagram of the correlation between the haulage speed and the power consumption of the shearer has two distinct clusters. Using the Gaussian mixture models method, the initial data array was clustered with the selection of two clusters corresponding to the working and shunting modes of the shearer. The resulting correlation diagrams are shown in Fig. 3.

With an increase in the haulage speed, the average active power consumed by the excavation area of the mine also increases. In the working mode of the shearer, a sharper increase in active power is observed with an increase in the haulage speed than in the shunting mode of operation (Fig. 3, a). An average level of correlation $(\mathrm{R}=0.63)$ is observed between the haulage speed and active power in the operating mode, and a strong correlation $(\mathrm{R}=0.8)$ is observed in the shunting mode. A lower degree of correlation in the operating mode may be a consequence of a significant scatter in the active power values due to the random nature of the change in the resistance of the destroyed coal mass. With an increase in the haulage speed of the shearer, an increase in the conveyor traffic flow is also observed (Fig. 3, b). The degree of correlation is average $(\mathrm{R}=0.55$ - in operating mode; $\mathrm{R}=0.42$ - in shunting mode). This degree of correlation is caused by the presence of frequency control of the conveyor drive, the purpose of which is to ensure the minimization of electricity consumption during coal transportation, while the task of controlling the shearer consists in maximizing coal production in the presence of restrictions on the conveyor transport capacity.

The histogram of the shearer haulage speed is shown in Fig. 4. According to the results of the analysis, the median value of the haulage speed of the SL 900 shearer in the studied excavation area in the working mode is about $8.67 \mathrm{~m} / \mathrm{min}$, and in the shunting mode $-19.78 \mathrm{~m} /$ min. 

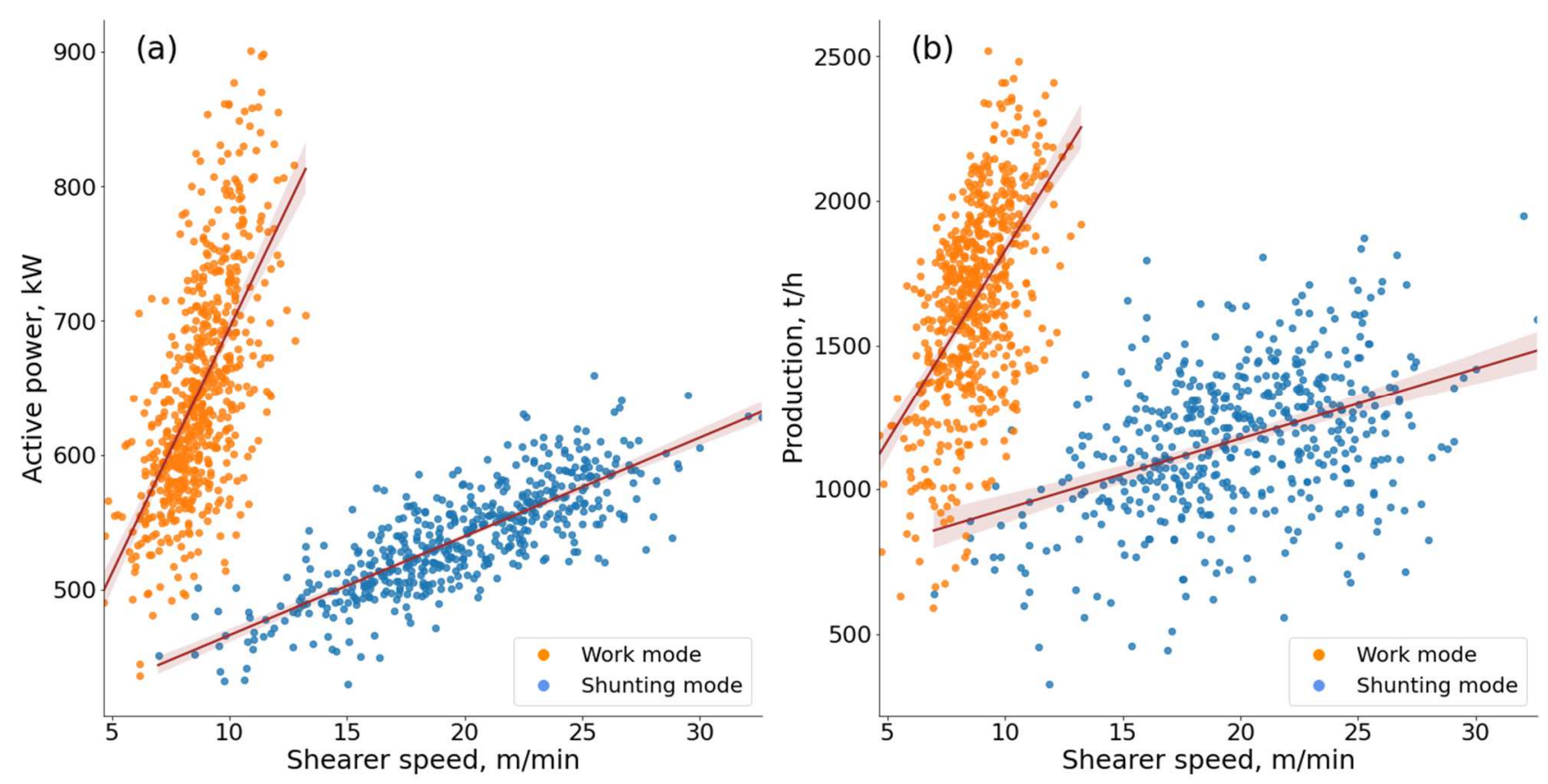

Fig. 3. Scatter plot of the shearer speed and active power (a) and the shearer speed and production (b).

An important indicator is the energy intensity of the shearer per 1 tonne of coal, the average value of which for the research object was $0.39 \mathrm{kWh} / \mathrm{t}$ - in operating mode and $0.46 \mathrm{kWh} / \mathrm{t}$ - in shunting mode. To assess the effect of the shearer haulage speed on the specific power consumption, a correlation diagram was constructed (Fig. 5).

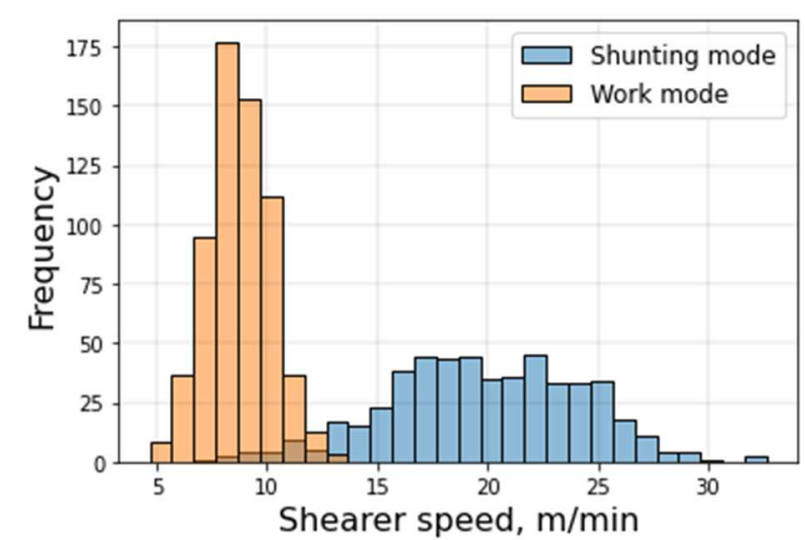

Fig. 4. Frequency histogram of the shearer speed.

A weak negative correlation was revealed between the haulage speed and specific power consumption $(\mathrm{R}=$ 0.21 and $\mathrm{R}=0.18$ - for the working and shunting modes of the shearer, respectively) - an increase in the haulage speed leads to a decrease in specific power consumption. The weak level of correlation, apparently, is explained by the fact that in the studied excavation area, the shearer operates with approximately one value of the working speed, deviations from which are associated with a random change in the density of the destroyed formation. When conducting an experiment with a shearer operating at different haulage speed, a stronger correlation can be expected.

\section{Conclusion}

The power consumption of the shearer is highly uneven. The magnitude of the electrical load is influenced by many random factors, which causes a wide range of power consumption values and a low degree of correlation with the technological parameters of the shearer operation. However, analysis of electricity consumption on a shift or day scale shows a direct relationship between the level of electricity consumption and the volume of coal mined. An increase in the productivity of the excavation area $(\mathrm{T})$ leads to an increase in power consumption (W) in accordance with the regression equation $\mathrm{W}=0.359 \cdot \mathrm{T}+65.564$ (Fig. 1 , a). 


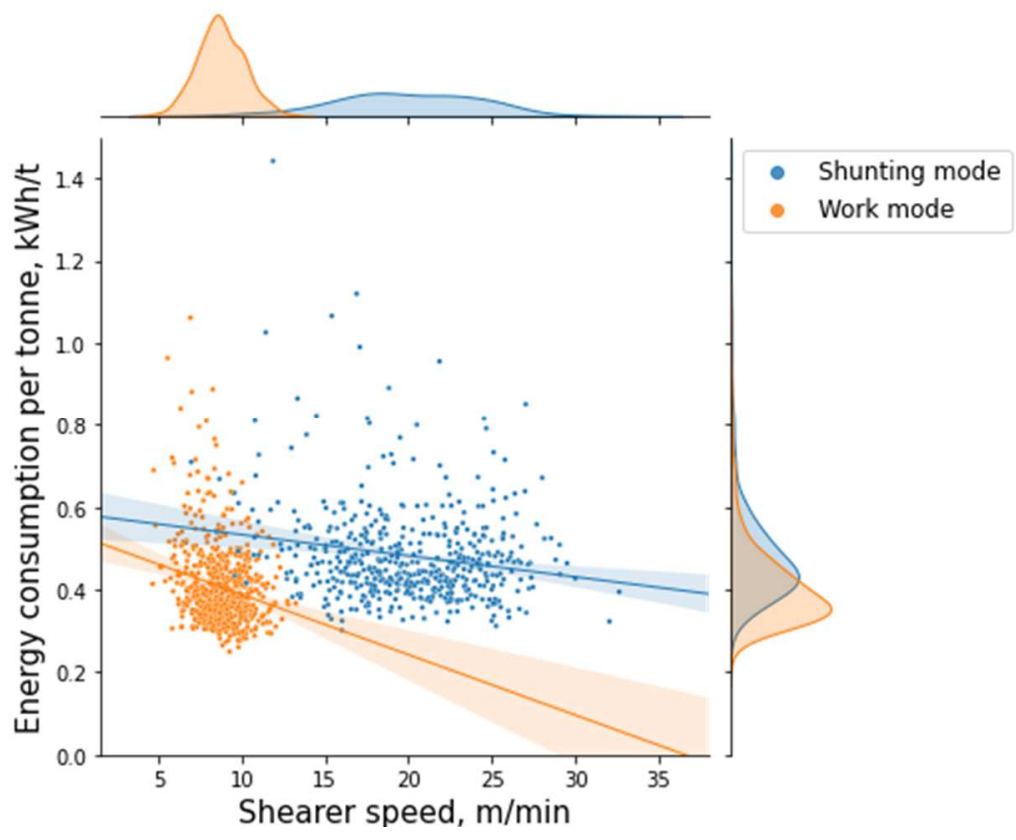

Fig. 5. Scatter plot of the shearer speed and energy consumption per tonne.

Technological characteristics and mining and geological conditions of the extraction area also have a significant impact on power consumption. An increase in the shearer haulage speed leads to an increase in the power consumption (Fig. 3) and helps to reduce the specific power consumption of the extraction area.

\section{Acknowledgments}

The reported study was funded by the Grant of the President of the Russian Federation for the state support of young Russian scientists, according to research projects No. MK-236.2020.8 and No. MK-86.2021.4.

\section{References}

1. Energeticheskii byulleten' 79. Coal demand forecasts: a vision for 2019 (2019) Retrieved from: https://ac.gov.ru/files/publication/a/26486.pdf

2. Order of the Government of the Russian Federation N 1582-r On approval of the Program for the development of the coal industry in Russia for the period up to 2035 (2020). Retrieved from http://www.consultant.ru/document/cons_doc_LAW _355241/

3. Energeticheskii byulleten' 84. Electricity: the impact of the COVID-19 pandemic (2020) Retrieved from https://ac.gov.ru/uploads/2-

Publications/Energo84_may2020.pdf

4. S.S. Kubrin, S.N. Reshetnyak, A.M. Bondarenko Bulletin of Kuzbass State Technical University 5, 97-100 (2017)

5. M.S. Karpenko Formation of an organizational mechanism for energy saving management at mining enterprises Doctoral dissertation National University of Science and Technology "MISIS" (2016)

6. A.G. Zakharova The laws of electricity consumption in the coal mines of Kuzbass Doctoral dissertation Kuzbass State Technical University (2006)

7. L. Barnewold, B.G. Lottermoser International Journal of Mining Science and Technology 30, 747757 (2020)

8. Y. Wu, M. Chen, K. Wang, G. Fu Safety Science 113, 9-18 (2019)

9. B.A. Gryadushii, V.V. Loboda, N.A. Chehlatii Ugol' Ukrainy 4, 14-19 (2013) 